\title{
O SETTING ANALÍTICO NA CLÍNICA COTIDIANA
}

Susana Marília Barbosa Galvão•

\section{RESUMO}

O presente estudo com o título "O setting analítico na clínica cotidiana" consiste em saber como o analisando pode dificultar seu tratamento no setting analítico. Elegeu como objetivo entender a dinâmica psicanalítica e suas variações no setting analítico. É uma pesquisa de natureza básica sendo que, quanto ao problema é qualitativa e quanto aos objetivos é explicativa descritiva. Sobre os procedimentos técnicos é bibliográfica. A respeito do método é hipotético dedutivo fundamentado em Karl Popper. A construção de novos paradigmas trouxe como consequência a necessidade de rearranjos e transformações nos tipos de interações entre os indivíduos.Constatou-se que a psicanálise vem sofrendo sucessivas transformações mas conserva a essência dos princípios fundamentados legados por Freud. Este estudo contou com as contribuições de autores como Bion (1992), Ferenczi (1919/1992), Freud (1895); Lacan (1988); Forbes (2004), Zimerman (2008) e outros.

Palavras chave: Setting analítico. Dinâmica psicanalítica. Analista. Analisando

\footnotetext{
- Doutora em Educação pela Facultad Interamericana de Ciencias Sociales. Asunción-PY. Contatos:
} E-mail: susi.barbosa@hotmail.com (62) 98113-3960 


\section{INTRODUÇÃO}

Setting analítico é entendido como um conjunto de recursos e procedimentos colocados no atendimento e oferecidos ao paciente. Está relacionado ao par analítico ou seja, analista e paciente.

No exercício da clínica psicanalítica depara-se com múltiplas faces do sofrimento psíquico. Situações às vezes inusitadas que, em alguns momentos, colocam em cheque o artesanal teórico construído.

Diante desse panorama, este estudo apresenta como problema a ser esclarecido por meio de referencial teórico saber como o analisando pode dificultar seu tratamento no setting analítico?

O interesse pelo tema surgiu de comentários informais vindos de pessoas que compartilham da falta de motivação no tratamento clínico, sendo que, algumas até desistem ou procuram por outro profissional.

A relevância deste estudo encontra apoio na releitura de autores e psicanalistas que trazem clareza na definição de conceitos enriquecedores para a prática analítica.

A finalidade deste estudo é entender a dinâmica psicanalítica e suas variações no setting analítico.

Quanto aos específicos, conhecer o perfil psicanalítico na clínica e descrever os mecanismos de defesas utilizados pelos analisandos.

Tem como hipótese, que o analisando pode estar dificultando seu tratamento através dos mecanismos de defesa, podendo também estar fingindo uma falsa ligação com o analista, mentindo sobre os dados relatados e ainda a possibilidade de um quadro depressivo.

No presente estudo, serão tecidas algumas considerações sobre o setting analítico do ponto de vista de alguns psicanalistas, o papel do analista, transferência e contratransferência. Em seguida, os autores trazem esclarecimentos sobre o 
processo terapêutico, o par analítico, os mecanismos de defesa, a função do silêncio em análise e atitudes do analisando que podem dificultar o tratamento.

Posteriormente, será apresenta a metodologia de pesquisa utilizada.

Encerra-se com a conclusão e em seguida, o registro de autores com suas respectivas obras, os quais fundamentam este estudo. 


\section{O PROCESSO ANALÍTICO}

Discutir sobre o manejo clínico na prática cotidiana psicanalítica, faz-se necessário retornar a Freud, Ferenczi e Winnicott.

\subsection{Setting analítico}

No texto "Recordar, repetir e elaborar" (1914) Freud faz um histórico do desenvolvimento da técnica psicanalítica, comentando sobre as consequências sofridas pela técnica psicanalítica desde os primórdios (FREUD, 1969).

As técnicas que Freud apresentou foram fruto de sua própria experiência, após anos de experiência atuando com seus pacientes. Com base nos resultados que obtinha, a prática ia sofrendo alterações.

Nos primórdios da psicanálise, Freud utilizou-se dos conhecimentos de Joseph Breuer sobre a hipnose. Este procedimento catártico iniciou nos estudos sobre a histeria em 1855. A terapia catártica foi uma descoberta de Breuer. Propunha que o paciente fosse hipnotizado e se baseava na ampliação da consciência que ocorre na hipnose. Tinha como alvo, a eliminação dos sintomas patológicos.

Freud fez alteração no método catártico, abandonando também a hipnose. Segundo Zimerman (2008) Freud substituiu a técnica pela Livre Associação de Ideias, também conhecida como Regra Fundamental.

Esta técnica consistia de uma pressão na fronte do paciente $\mathrm{e}$ espontaneamente deveriam dizer o que the viesse a mente sem restrições ou censuras, mesmo que não tivesse sentido.

Segundo Zimerman (2008) a técnica "visava acessar as camadas do inconsciente que retinham repressões, agora não só os traumas que realmente teriam acontecido mas também as fantasias e desejos" (p.32). 
Freud formulou uma série de recursos técnicos além da associação livre como também a interpretação dos sonhos, o significado dos atos falhos e sintomas, lapsos de linguagem.

Uma das recomendações feitas por Freud aos médicos é de que " deve-se manter a atenção uniformemente suspensa, em face de tudo que se escuta" (1912, p. 125).

Sugere também que o analista não fixe sua atenção em determinado ponto, pois, "desta maneira estará arriscando a nunca descobrir além do que já sabe" ( $p$. 126). Tudo o que o analista ouve, deve ser guardado na memória para serem compreendidas posteriormente.

Esta regra denominada atenção flutuante diz respeito a simplesmente escutar, sem privilegiar qualquer aspecto da fala do analisante. Agindo assim, estará preparado para as exigências do tratamento. As informações desconexas serão lembradas quando algo novo for trazido pelo paciente.

Menciona também sobre a importância do distanciamento emocional com o paciente. Outro ponto importante foi exercitar a auto análise para impedir que sua próprias resistências interfiram no material trazido pelo paciente.

No período de 1912 a 1915, segundo Zimerman (2008), Freud propôs aos médicos que exerciam a psicanálise as suas cinco regras teóricas: livre associação de ideias, a da abstinência, atenção flutuante, a da neutralidade e a do amor a verdade.

O setting especial construído por Freud tinha um número mínimo de sessões semanais enfatizando segundo Zimerman (2008) um conjunto de fenômenos que necessariamente estariam sempre presentes na análise.

Por outro lado, Ferenczi revela um profissional inclinado a privilegiar a mutualidade, a igualdade e a simetria entre o analista e o paciente. Freud apresenta uma posição patriarcal, intelectualista e autoritária, enquanto Ferenczi propõe um movimento afetivo e igualitário.

Mais tarde, em 1918, em uma conferência em Budapeste, Ferenczi afirma: "todo método psicanalítico apoia-se na regra fundamental formada por Freud, ou 
seja, a obrigação para o paciente de comunicar tudo o que the vem ao espírito no decorrer da sessão de análise" (1919/1992, p.357).

$\mathrm{Na}$ sequência, ele fala da forma de como o analista deve responder a perguntas formuladas pelos pacientes. Afirma que "o psicanalista não tem mais o direito de ser, à sua moda, afável e compassivo ou rude e grosseiro na expectativa de que o psiquismo do paciente se adapte ao caráter do médico" (1919/1992, p. 365)

Winnicott (1963) foi um defensor da manutenção do setting clássico. Afirma que a modificação da técnica é necessária somente em casos de tratamentos graves.

Para este autor, o setting é uma metáfora de cuidados maternos. Na visão winnicottiana o analista deve ser um analista suficientemente bom, por ter uma preocupação materna primária, proporcionando ao paciente um holding adequado, permitindo que se transforme em um ser que experimente a si mesmo, em que seu verdadeiro self possa se manifestar.

Depois de Ferenczi vieram os Kleinianos que teve como precursora Melanie Klein com suas contribuições técnicas com Riviére.

Winnicott, após sair do círculo kleiniano, criou suas próprias concepções originais.

Considera constituinte de um holding, o conforto físico que se pode oferecer aos pacientes no consultório (rotina de horários, pontualidade) como também a postura do analista, compreender sem atuar, permitindo ao paciente que saia mais integrado.

O conceito de holding é similar ao de Bion, segundo Zimerman (2008), "representa ser uma peça técnica fundamental na construção do vínculo analistapaciente" (p.39)

Um conceito relevante de Winnicott sobre a técnica analítica é a concepção de verdadeiro e falso self em um mesmo sujeito. No setting winnicottiano era flexível se ultrapasse os 50 minutos. 
Sobre o setting "recria-se um ambiente íntimo e familiar, evocando uma primitiva maternagem, a um mesmo tempo que se exclui todo o contato e gratificações diretas que não sejam as psíquicas" (WINNICOTT IN ZIMERMAN, 2008, p. 40).

Bion, discípulo de Klein é considerado segundo Zimerman (2008) inovador da prática psicanalítica. Dedicou-se a dinâmica de grupos e interessava-se pelos aspectos sociais.

Não publicou nada específico sobre a técnica psicanalítica, mas conservou o que aprendeu de Freud e Klein. Não os contestou, apenas criou ideias teóricas novas. Mérito especial que cabe a Bion é ter enfatizado que:

Toda análise é um processo de natureza vincular entre duas pessoas que vão enfrentar muitas angústias diante dessas verdades [...] impõe que o analista possua aquilo que ele denomina condições necessárias mínimas ( BION APUD ZIMERMAN, 2008, p. 41)

Bion não fala de cura analítica e sim, crescimento mental, considerando que uma análise não termina com uma cura de sintomas, mas expande, evolui, sem um término definitivo.

\subsection{A ética psicanalítica}

Freud postulava que a ética corresponde às recomendações de que o analista deve ser como um espelho que irá refletir as revelações do paciente. E para que isto seja possível e ético, ele precisa deixar de lado suas convicções e desejos. Freud ao postular a existência das pulsões de vida (Eros) e de morte (Tânatos), aponta para a coexistência do bem e do mal no homem.

De acordo com Lacan (1959-1960), a psicanálise trouxe novas possibilidades para se pensar a ética. A psicanálise vem mostrar que a escolha que o homem pode fazer entre o bem e o mal, não é uma escolha consciente, produto de um livre arbítrio. Esta escolha, de acordo com a psicanálise é determinada pelo inconsciente, ou seja, a psicanalise entende que o bem e o mal são singularidades da espécie humana.

A ética psicanalítica está intrínseca ao fazer analítico. A falta de ética põe ser entendida quando o analista antecipa respostas ao analisando. Quando este 
desejo interfere no desejo do analisando, quer dizer que está rompendo com a ética, confirma Rosa e Rosa (2009).

[...] a ética da psicanálise é uma ética relativa ao discurso do psicanalista, em que o desejo do psicanalista está aí eticamente implicado, não como desejo de fazer o bem, mas como um operador deste discurso. A partir daí, podemos dizer que, se há uma ética da psicanálise, ela não pode estar desarticulada da clínica psicanalítica, que é a clínica do sujeito. Se há algum bem relativo à psicanálise, este bem se encontra na fala, na linguagem, na palavra, no dizer. Portanto para a psicanálise, ética, não poderia ser outra, se não a do bem dizer. Inúmeras situações clínicas nos remetem à ética (p.267).

\subsection{0 papel do analista}

Desde os tempos iniciais, tem-se a preocupação com a formação do analista. Associação Psicanalítica Internacional (IPA) determina a obrigatoriedade da análise pessoal para a formação psicanalítica.

No ano de 1925 foi instituída na Associação Psicanalítica Internacional (IPA) a obrigatoriedade da análise pessoal para a formação psicanalítica.

Ao longo dos anos, a IPA havia se transformado num vasto aparelho atormentado pelo culto da personalidade [...] reencontrou-se assim, na análise didática, o poder da sugestão que Freud havia banido da prática da psicanálise. Em consequência disso, seus herdeiros passaram a correr o risco de se transformar em discípulos devotos de mestres medíocres, que por se tornarem por nós profetas, aceitaram em silêncio a esclerose institucional (ROUDINESCO \& PLON 1998, p.18)

A escuta da psicanálise encontra sua vitalidade na capacidade do analista reconhecer o valor e a necessidade de ser ele próprio escutado.

A possibilidade de escuta está no próprio desejo do analista recuperado a cada momento pelo trânsito das associações que lhe permitem reconhecer seu desejo pessoal. "Jogo para poder a ele renunciar levando-o a não ter a necessidade de querer assegurar seu lugar, nem pela rigidez do setting, nem pela rigidez do gesto" (ROUDINESCO \& PLON, 1998, p. 4)

Ainda com Roudinesco e Plon (1998): 
A versão lendária do nascimento da psicanálise atribui sua origem a duas mulheres [...] a primeira tratada por Joseph Breuer, atribui a invenção da terapia pela fala, e de segunda, tratada por Freud, disseram que ela permitiu a invenção de uma clinica da escuta, obrigando o médico a renunciar a uma observação direta e a se manter recuado, atrás do paciente (p. 604-605).

O trabalho psicanalítico é sustentado pela associação livre do analisando, ou seja, a escuta do analista que recebe as comunicações do analisando, de forma livre.

Assim como o paciente deve comunicar tudo o que sua introspecção o revela, abstendo-se de toda reflexão lógica ou afetiva que o induza a fazer uma seleção, também o médico deverá colocar-se em situação de utilizar tudo o que é fornecido pelo paciente para a interpretação e a descoberta do inconsciente oculto, sem substituir com a sua própria censura a seleção a qual o paciente renunciou (p. 1657)

Ferenczi (19861989) ressalta duas qualidades complementares exigidas do analista: a sensibilidade constante e a apreciação consciente da situação dinâmica (entre analista e analisando) "ponderam e regulam a prática analítica seguindo a elasticidade" (p. 99)

Para que a análise tenha eficácia, o analista precisa detectar, sem fazer seleção de conteúdo, deve fazer uso de tudo o que the é dito para fins de interpretação para identificar o material oculto.

Segundo Zimerman (1999) ter a teoria e a técnica não garante a eficácia de uma análise, por mais bagagem de conhecimentos que tenha. Ele precisa ter uma atitude psicanalítica desenvolvida em sua análise pessoal.

Segundo Bion (1992) é importante enfrentar as angústias e os imprevistos provenientes do inconsciente do paciente em análise e analista

De acordo com Rocha (1995) para se tornar um psicanalista é necessário tenha tido uma boa formação, que antes tenha sido paciente, precisa ter elaborado seus conflitos, conteúdos para não serem projetados inconscientemente sobre o paciente. 


\subsubsection{A escuta do analista}

A escuta em psicanálise ganha seu espaço nas várias de comunicação. São elas:

a) A escuta dos gestos e atitudes

No momento da chegada do paciente, o analisando já manifesta gestos e atitudes atrás da linguagem pré verbal. Desde o jeito de sentar-se, cumprimentar, expressão facial.

Segundo Zimerman (2008) " o analista deve estar atento para a linguagem não verbal contida e oculta no discurso verbal" (p. 160).

b) A escuta do corpo

Freud já havia descoberto que o ego é corporal.

De acordo com Zimerman (2008) os psicanalistas da escola psicossomática de Paris estão atentos na leitura das mensagens psíquicas emitidas pelo corpo.

Os psicanalistas devem estar atentos para fazerem a leitura das mensagens psíquicas emitidas pelo corpo. São eles: a imagem corporal, cuidados corporais, sintomas conversivos, hipocondrias e somatização.

c) A escuta intuitiva

A importância da capacidade de intuição do analista foi atribuída a Bion.

É importante que a intuição seja aflorada, conforme postula o pensamento bioniano, o que requer preparo do analista para atender seu paciente.

O analista deveria entrar na sessão em um estado psíquico especial, sem memória, sem desejo e sem ânsia de entendimento' Ao cunhar a expressão " sem memória, sem desejo", o pensamento bioniano levou às últimas conseqüências o estado de atenção flutuante preconizado por Freud como próprio da disciplina mental que o analista deve cultivar no exercício de seu ofício.

d) A fala 
Ao se desligar da prática da hipnose entre 1880 e 1895 que Freud passou pela catarse, para inventar o método psicanalítico propriamente dito, baseou-se na associação livre, ou seja, na fala e na linguagem.

Ao falar, o sujeito comunica muito mais do que aquilo que propôs. De acordo com Quinet (2009) o inconsciente busca ser escutado e manifesta-se através dos sonhos, atos falhos e sintomas.

Mas a escuta pode se dar nas palavras ditas ou silenciadas e que ao mesmo tempo abrem espaço para a significação.

Desse modo, segundo a formulação lacaniana, o ato de permanecer em silêncio não confere à pessoa uma ausência de linguagem, uma vez que o silêncio sempre comunica algo que não pôde se manifestar no plano verbal.

Em análise, Lacan apud Macey (1988) reconhece dois tipos de fala. As primeiras manifestações do paciente são dominadas por seu narcisismo na tentativa de seduzir o analista. Caracteriza-se aí na fala vazia ou seja, o sujeito se perde na linguagem como objeto, sendo um obstáculo para a transferência positiva.

A fala vazia se manifesta na resistência do inconsciente que ao invés de centrar na função da revelação, liga-se a mediação. A resistência se produz no momento em que a fala de revelação não se diz. Ainda com Lacan apud Macey (1988), se a fala funciona então como mediação, é por não ter se realizado como revelação.

A fala plena é a aproximação da verdade do desejo e portanto, substitui a mediação pela revelação.

\subsection{Transferência e contratransferência}

A palavra transferência tem origem latina e significa transportar, transferir, deslocar, passar de um para outro, valores ou signos. Segundo Gutierra, (2003, p. 80), "articula-se à ideia de repetição, relacionada às vivências infantis atualizadas nas relações humanas, não apenas no setting analítico".

Segundo Laplanche e Pontalis, a transferência: 
Designa em psicanálise o processo pelo qual os desejos inconscientes se atualizam sobre determinados objetos no quadro de um certo tipo de relação estabelecida com eles e, eminentemente, no quadro da relação analítica. Trata-se de uma repetição de protótipos infantis vivida com uma sensação de atualidade acentuada. (...) $\mathrm{Na}$ origem, a transferência, para Freud, não passa, pelo menos no plano teórico, de um caso particular de deslocamento do afeto de uma representação para outra. (2001, p. 514).

Freud detectou o fenômeno psicológico da transferência a partir das dificuldades que encontrava para curar pacientes neuróticos. Durante a análise, percebia que esses pacientes apresentavam uma especial disposição psicológica para a sugestão, isto é, para que o médico exercesse influência mental sobre eles.

Segundo Maurano (2006), Freud percebeu o fenômeno espontâneo da transferência e a complexidade dessa relação na paciente Anna O. com o médico Breuer, que o levou a renunciar à hipnose e criar o método psicanalítico.

De acordo com essa autora:

\begin{abstract}
O fenômeno da transferência é a chave da invenção desse novo método de tratamento. A Überträgung, termo alemão que além de transferência significa também transmissão, contágio, tradução, versão, e até audição, ganhará, enquanto conceito psicanalítico, o sentido de estabelecimento de um laço afetivo intenso, que se instaura de forma quase automática e independente da realidade, na relação com o médico, revelando o pivô em torno do qual gira a organização subjetiva do paciente. (MAURANO, 2006, p. 16).
\end{abstract}

Uma das noções mais conhecidas, em relação ao conceito de transferência, é o que remete em Lacan à fórmula: "Sujeito Suposto Saber", na medida em que nela se localiza a instauração da dinâmica do tratamento psicanalítico. No seminário "Os quatro conceitos fundamentais da psicanálise" afirma: "A transferência é impensável se não se tomar seu início no sujeito suposto saber (...). O sujeito entra no jogo, a partir desse suporte fundamental - o sujeito é suposto saber, simplesmente por ser sujeito do desejo". (OLIVÉ, citando LACAN, em seu artigo: Contribuições sobre transferência, $s / p$ ).

Em 1960/1961, Lacan introduz em seu Seminário 8, as noções de sujeito suposto saber e o desejo do analista. $O$ analista, início de uma análise é colocado pelo analisante numa posição de amado, aquele que tem o saber, que tem a resposta para o seu sofrimento. Já o analista, deve direcionar o tratamento não ocupando esse lugar do sujeito que tem este suposto saber. Segundo Lacan, quem 
tem que ter este saber sobre o sofrimento, sobre seu inconsciente, é o próprio sujeito.

Sujeito suposto saber é "a base de tudo o que se apresenta em termos de transferência analítica. Desde que haja em algum lugar o sujeito suposto saber [...] há transferência" (LACAN, 1988/1964, p. 220)

Segundo Lacan (1992) somente não dando a resposta para seu paciente, colocando-o para falar de seu sofrimento é que permitirá que o analisando caminhe do amor ao desejo numa análise. Saindo do lugar de amado para o lugar de amante, daquele que vai em busca do que Ihe falta. Esta busca é que permitirá que se dê passagem amor ao desejo. $O$ analista precisa estar regido do desejo de analista para fazer surgir o desejo do sujeito, desejo de colocar o paciente para associar livremente.

Segundo Lacan "Há saber e no Outro". O sujeito do desejo tem o saber colocado em outro lugar, por isso o sujeito procura localizá-lo, ou seja, procura darIhe uma sustentação imaginária em relação a algum Outro real.

Sobre a Contratransferência, o prefixo contra, pode ser entendido com dois significados diferentes: oposto e paralelo. No primeiro significado, 'contra' é o que se opõe: como por exemplo, ataque e contra-ataque. Na outra acepção, o prefixo é empregado como o que contrabalança em busca de equilíbrio: no mesmo sentido de ponto e contraponto, como sugere Sandler (1986).

Essas duas acepções se referem a um ato contínuo, pois assim como o analisado, o analista também realiza transferência, como conseqüência ou reação à transferência do analisado. A transferência provém do paciente e a contratransferência é a resposta do analista à transferência do analisado. Isto implica que o ponto de partida seja a transferência do paciente, sobre a qual o analista trabalha contratransferencialmente com ética e profissionalismo para o sucesso do tratamento.

Segundo Laplanche e Pontalis, "Contratransferência é o conjunto das reações inconscientes do analista à pessoa do analisado e, mais particularmente, à transferência deste". (2001, p. 102). 
De acordo com Morgado, a contratransferência é essencial no tratamento, desde que o analista saiba manejá-la para colocá-la a serviço do trabalho analítico:

\begin{abstract}
Se a transferência do paciente é a reedição inconsciente de clichês estereotípicos de relação, a contratransferência é a resposta inconsciente do analista aos efeitos por ela produzidos em sua psique. Se os sentimentos transferenciais utilizam a relação presente para se expressar, o analista também atualiza fixações libidinais quando responde contratransferencialmente. Mas 0 analista não deve sufocar a contratransferência, ou seja, não deve se defender da transferência do paciente; deve, ao contrário, aceitá-la, conferindo importância aos sentimentos do paciente. Em síntese, deve permitir que seus sentimentos fluam, aceitando a própria contratransferência. Todavia, não pode permitir que flua desordenadamente: precisa controlá-la. (2002, p. 99).
\end{abstract}

O analista deve conferir importância a esses sentimentos, considerando que são sentimentos pertencentes às relações originais e, portanto precisa estar atento para não responder contratransferencialmente a eles.

Conforme afirma Morgado (2002, p. 100): "O médico não deve retribuir esses sentimentos. Agir de modo contrário implica impedir que o paciente ressignifique seus conflitos, implica reiterar a transferência em vez de superá-la".

Ao analisar a contratransferência nas relações pedagógicas, Morgado afirma que o campo transferencial pode não ser percebido porque é como se já estivesse ali presente e independesse daquela relação:

A relação analítica visa à dissolução da transferência. Nas outras relações humanas, o campo transferencial passa desapercebido. Ao contrário da relação analítica, elas estimulam a repetição dos imagos originais, transformados em ideais sociais. $E$, esses imagos podem ser ressignificados, sem que para isso concorra qualquer esforço consciente das partes envolvidas. (MORGADO, 2002, p.104).

De acordo com Heimann (1995) apud Isolan (2005) é importante que o psicanalista compreenda as projeções do paciente. Precisa controlar os sentimentos que nele foram despertados, não podendo descarregá-los como faz o paciente.

Ao final da análise, de acordo com Lacan (1992) o analista deve ter conduzido a cura não ocupando o lugar de suposto saber. Ao final do tratamento o analista se torna um resto sem função e sem importância para seu paciente. 


\subsubsection{Tipos de transferência}

Freud (1912) descreve que não se pode compreender o termo transferência como uma resistência ao tratamento. Tem-se que pensar na transferência enquanto positiva, negativa e erótica.

1) Positiva: Freud conceituou da seguinte forma: "transferência positiva é ainda divisível em transferência de sentimentos amistosos ou afetuosos, que são admissíveis à consciência, e transferência de prolongamentos desses sentimentos do inconsciente" (FREUD, 1912, p. 140).

O paciente fica mais suscetível à influência do analista, pois, nutre por ele sentimento de respeito, admiração, empatia atribuindo credibilidade às suas comunicações. Faz baixar as resistências e se esforçar por associar livremente.

2) Negativa: Caracteriza-se por sentimentos hostis do analisante em relação ao analista vinculada ao que o paciente resiste em dizer. Aparece também como forma de defesa contra o aparecimento da transferência positiva. Segundo Freud (1912) o analista deve se preocupar com este tipo de transferência, pois, este tipo de vinculação reflete, de forma direta, a resistência ao trabalho analítico. $O$ analista precisa saber manejar bem para que não paralise o tratamento psicanalítico.

3) Erótica: É aquela em que o analisando transfere para a pessoa do analista sentimento de amor. Esse sentimento acontece quando o vínculo transferencial assume caráter sexual.

\footnotetext{
O analista deve reconhecer que o enamoramento da paciente é induzido pela situação analítica de não deve ser atribuído aos encantos de sua própria pessoa; de maneira que não tem nenhum motivo para orgulhar-se de tal conquista. Para a paciente há duas alternativas: abandonar o tratamento psicanalítico ou aceitar enamorar-se de seu médico como um destino inelutável (FREUD, 1914, p. 377, 378).
}

Freud (1915) em seu texto "Observações acerca do amor transferencial" afirma que é desastroso para análise o anseio da paciente em satisfazer ou reprimir esse amor. "O caminho em que o analista deve seguir não é nenhum destes; é um caminho para o qual não existe modelo na vida real" (FREUD, 1915, p, 381). 
Deve-se tomar cuidado para não se afastar do amor transferencial, repelí-lo ou torná-lo desagradável para a paciente; mas deve de modo igualmente resoluto, recusar-Ihe qualquer retribuição.

\section{O PROCESSO TERAPÊUTICO: paciente e analista}

É de praxe o analisando achar que está chegando ao final de uma análise. Há muitas implicações para se entrar em análise. Entrar em análise é mudar de posição subjetiva; é sair de uma moral de costumes e se instalar na ética do desejo.

Neste processo, a clínica vai sofrendo variações tanto do analisando quanto do analista.

\subsection{Mecanismos de defesa}

Com o crescimento da escola kleiniana, a psicanálise adquiriu novas concepções. Surgiram então os mecanismos defensivos do ego.

Segundo Anna Freud (1982) a palavra defesa é empregada por Freud "[..] para descrever a luta do ego contra ideias ou afetos dolorosos ou insuportáveis" ( $p$. 36).

Estes mecanismos entram em ação para permitir que alguns componentes dos conteúdos mentais indesejáveis cheguem a consciência de forma disfarçada. " Quer se trate de medo do mundo exterior ou medo do superego, a ansiedade é que desencadeia sempre o processo defensivo" (FREUD, A. 1982, p. 49).

São eles:

a) Formação reativa: o impulso indesejável é mantido inconsciente devido a forte adesão no sentido contrário.

Formações reativas são atitudes opostas ao desejo original reprimido, isto é, contracatexias. "[...] são capazes de usar impulsos cujos objetivos se opõem aos objetivos do impulso original" (FENICHEL, 1999, p.141).

b) Projeção 
Segundo Laplanche e Pontalis (2001), Freud define a projeção como uma defesa primária, na qual o ego procura no exterior a origem de algo que lhe causa desprazer.

"A projeção aparece como uma defesa, como a atribuição ao outro - pessoa ou coisa - de qualidades, de sentimentos, de desejos que o sujeito recusa ou desconhece em si" (LAPLANCHE; PONTALIS, 2001, p.376)

Manifesta-se quando o ego não aceita reconhecer um impulso inaceitável do id e o atribui a outra pessoa.

c) Introjeção

O termo introjeção foi descrito inicialmente, por Ferenczi. Segundo Laplanche e Pontalis (2001), Freud refere-se a introjeção como incorporação. Na busca de suprir as necessidades de sobrevivência e satisfação, esta incorporação é entendida como um ato oral. No processo de formação do ego, este incorpora ou introjeta objetos exteriores, na tentativa que estes possam lhe proporcionar prazer.

d) Sublimação

Em 1908, Freud fala da sublimação como uma palavra utilizada pra definir atividades aceitas socialmente como corriqueiras que não tenham uma ligação direta com a sexualidade.

Há uma troca do objetivo ou do objeto sexual, por algo aceito socialmente. A pulsão sexual põe à disposição do trabalho cultural quantidades de força extraordinariamente grandes, e isto graças à particularidade, especialmente acentuada nela, de poder deslocar a sua meta sem perder, quanto ao essencial, a sua intensidade. Chama-se a esta capacidade de trocar a meta sexual originária por outra meta, que já não é sexual, mas que psiquicamente se aparenta com ela, capacidade de sublimação. (FREUD, 1987[1908], p. 193).

Sublimação é uma defesa bem sucedida. Com a permissão do ego que transforma a finalidade ou o objeto pulsional, a pulsão é descarregada (FENICHEL, 1999).

a) Recalcamento/ repressão 
De acordo com Laplanche e Pontalis (2001), recalcamento ou repressão é um termo utilizado por Freud, inicialmente como sinônimo de defesa, que se acreditava existir somente na histeria.

Segundo Freud (1987) a repressão se apresenta quando algo é mantido afastado da consciência. A possibilidade de retorno do recalcado ocorre quando este "retorna" por vias de escape, "disfarçados", na forma de sintomas, atos falhos, chistes e sonhos.

É a operação psíquica que pretende fazer desaparecer da consciência, impulsos ameaçadores, conteúdos desagradáveis ou inoportunos.

b) Racionalização

Racionalização é o mecanismo que revela uma maneira de o sujeito explicar utilizando a lógica, uma atitude, uma idéia ou um sentimento.

A racionalização aparece tanto nos pensamento normais, quanto nos delírios. Não é um mecanismo de defesa no sentido estrito do termo, embora tenha uma função defensiva "[...] porque não é dirigida diretamente contra a satisfação pulsional, mas antes vem disfarçar secundariamente os diversos elementos do conflito defensivo". (LAPLANCHE \& PONTALIS, 2001, p.423). Já para Freud a racionalização se dá como uma ação do superego para reforçar as defesas do ego e não aparece nos delírios, mas é uma elaboração secundária. (FREUD, 1987).

É uma forma de substituir por boas razões uma determinada conduta que exija explicações da parte de quem a adota.

c) Negação

Negação na concepção de Freud (1987[1925]) é a maneira que o sujeito tem de retratar uma percepção do mundo exterior que é incômoda ao ego. Essa negação, na verdade confirma qual é o estímulo angustiante, no momento em que ele é negado.

d) Isolamento

De acordo com Freud (1987 [1915], o isolamento tem a função de servir como um afastamento de um pensamento, para que este não seja associada a uma 
outra idéia que foi reprimida, então o neurótico isola a idéia indesejada para proteger o ego de algo que lhe é incômodo.

e) Idealização

Segundo Freud ([1914]1974), “[...] a idealização é um processo que diz respeito ao objeto, e pelo qual este é engrandecido e exaltado psiquicamente sem alteração da sua natureza. A idealização é tão possível no domínio da libido do ego como no da libido objetal" (Freud, 1974, p.94).

A idealização é marcada pelo narcisismo, visto que pode voltar a libido para o ego e é parte constituinte do sujeito, na medida em que o objeto idealizado contribui para a formação as instâncias ideais.

\section{f) Anulação}

No mecanismo da anulação aqueles conteúdos que são incômodos ao ego, são tratados como se nunca tivessem existido e são substituídos por outros, tendo como função apagar os primeiros. É um mecanismo regressivo em que se altera o real por meio do pensamento mágico. Nas palavras de Bergeret, "[...] consiste em desfazer o que se fez". (BERGERET, 2006, p.104).

\section{g) Deslocamento}

Freud define o deslocamento como uma operação na qual a idéia reprimida é associada a outro significante e o afeto dessa idéia é colocado em um representante que não ameace a integridade do ego e, ainda assim, possa satisfazer a pulsão.

[...] o aparelho inconsciente que atua por meio dos deslocamentos de quantidades. Parece provável, que no começo, o princípio do desprazer regule automaticamente o deslocamento dos investimentos, mas é muito possível que a consciência dessas qualidades introduza, além disso, uma segunda regulação, mais discriminadora, que pode até opor-se à primeira e que e que aperfeiçoa a eficiência do aparelho, capacitando-o, em contradição com seu plano original, a investir e elaborar até mesmo aquilo que está associado à liberação de desprazer. (FREUD, 1987, p.557).

h) Resistência

O termo resistência foi introduzido por Freud, sendo interpretado como um dificultador do acesso do sujeito ao seu inconsciente. Inicialmente, segundo 
Laplanche e Pontalis ( 2003) a resistência apareceu como um obstáculo a rememoração, ou seja, dificuldade do material recalcado vir à consciência.

Com o surgimento da $2^{\text {a }}$ tópica, Freud mencionou as noções de id, ego e superego, momento em que a resistência passou a ser definida como um mecanismo de defesa. O que era conflito defensivo operado pelo sistema pré consciente/consciente sobre o inconsciente, deslocou-se para a oposição do ego recalcado.

A falsa ligação foi nomeada por Freud (1895/2006무) como uma forma de resistência no funcionamento sintomático. As representações aflitivas são vinculadas ao analista "quando a relação entre o paciente e o analista é perturbada e constitui o pior obstáculo com que podemos comparar" (FREUD, 1895, p.312).

Esta falsa ligação que é um obstáculo a análise, decorre da relação entre a presença do analista e o paciente. Supõe que seja pela falta de confiança no analista, ou seja, não inspira confiança no paciente; assim as representações que o afligem não são lembrados por meio da fala e criam obstáculos devido a autocensura do paciente. Para superar, precisará contar com a postura do analista (FREUD, 1895).

\footnotetext{
Além das motivações intelectuais que mobilizamos para superar a resistência, há um fator afetivo, a influência pessoal do médico, que raramente podemos dispensar, e em diversos casos só este último fator está em condição de eliminar a resistência (p. 296)
}

A resistência já foi considerada um fator obstrutivo que deveria ser vencida.

De acordo com Zimerman (2008) a resistência continua sendo manifestada pelo paciente, porém, é vista atualmente de forma benéfica, com mais clareza, ou seja, " mostra como o paciente constitui o seu mundo interior e de como ele age no mundo exterior" (ZIMERMAN, 2008, p. 26).

Lacan (2002) para finalizar os efeitos produzidos na análise, afirma que a resistência possível de acontecer é a do próprio psicanalista. Se ao acaso o analisante resistir, cabe ao analista agir nos pontos de menor resistência e metaforizando, agir como um bom cozinheiro que sabe cortar bem o animal. 


\subsection{Estados depressivos}

Os quadros clínicos de depressão estão adquirindo uma crescente importância na prática analítica.

As depressões segundo Zimerman (2008) podem ser classificadas em:

a) Atípicas: resulta de uma crise existencial e não respondem bem a medicação.

b) Endógena: resulta de causas orgânicas mas podem também ser desencadeadas por fatores ambientais.

c) Distímica: Depressão crônica.

Tem-se a manifestação do vários estado mentais como a tristeza, luto, melancolia, posição depressiva.

De acordo com Zimerman (2008) a posição depressiva se refere a um estado mental que o paciente adquire no decurso da análise que, embora penoso é positivo porque "denota que o analisando está integrando os aspectos dissociados de sua personalidade, assim como adquirindo condições para sentir gratidão e reconhecer seu quinhão de responsabilidade e demais culpas" (p.100).

Nos casos em que está justificado o uso de medicação antidepressiva, é necessário que o analista tenha em mente que o mais indicado é que haja uma complementação entre o uso medicamentoso e a concomitância da terapia analítica. Sem o auxílio de um ou outro, perde em muito a eficácia.

\subsection{A mentira}

Em análise, a mentira comporta um instrumento de significações. Ela é vista como um meio de comunicação, visando a uma não comunicação ao emprego das falsificações.

De acordo com Zimerman (2008) elas possuem variâncias e podem se apresentar de diversas formas e performances: 
a) Mentira comum (hipocrisia social)

b) Mentira piedosa

c) Como forma de evitar sentir vergonha

d) Um mentira para fugir de um perseguidor (discurso mentiroso e pedagogo)

e) Mentira psicopática (uso da má fé)

f) Mentira maníaca

g) Como forma de perversão (uma mistura do real com o imaginário).

Segundo Zimerman, merece preocupação quando o analista percebe que há um excesso de mentiras do paciente para sí próprio.

\subsection{0 silêncio na análise}

O silêncio constitui uma fato analítico de relevante importância no desenrolar de um tratamento. Fazer silêncio em um momento ou outro na sessão equivale segundo Násio ( 2010 ) a mostrar o inconsciente pulsional e a convocá-lo novamente.

Ainda com Násio (2010) as primeiras contribuições de Frenczi e Abraham interpretam a recusa de falar do paciente como a manifestação de um desejo erótico anal. Ferenczi em seu artigo (1910) associa o fato de se calar retendo as palavras e a retenção da expulsão anal.

A partir das observações clínicas de pacientes gagos e apoiando-se em certas observações de Ernest Jones, ele explica a aparição do silêncio como a vontade e guardar ciumentamente o tesouro que as palavras, à maneira de excrementos exprimem no inconsciente (FERENCZI, 1910, p, $11)$.

Mais tarde, em 1949 apresentou as variantes do silêncio associado aos níveis pulsionais que existem no desenvolvimento libidinal.

Em 1919 Abraham aborda o silêncio como um defesa contra o erotismo oral. 
Segundo Winnicott (1963/1990) o silêncio toma o seu valor de ciência "[...] não é simplesmente negativo, mas vale como além da palavra. O silêncio é um dizer que faz surgir um sentido, a saber, na pausa, nos intervalos, nas reticências" ( $p$. 322).

Orlandi (1997) traz sua contribuição afirmando que o silêncio não é vazio. Indica uma totalidade significativa, a qual leva a uma compreensão deste vazio da linguagem e não como falta.

A palavra silêncio etmologicamente vem do latim silentiu que segundo Ferreira (1999) é o estado de quem cala, privação de falar.

Para Orlandi (1997, p. 89) "o silêncio é real do discurso. Segundo Lacan (1954) o silêncio é um dizer que faz surgir um sentido, a saber, na pausa, nos intervalos e reticências "[...] o silêncio anuncia o discurso do inconsciente" (p.322).

\subsection{0 analista como modelo de identificação}

A psicanálise clássica preconizava que a ação terapêutica analítica depende unicamente das interpretações dirigidas ao inconsciente do paciente que "levam os insights, cuja elaboração continuada abre caminho para a cura" (ZIMERMAN, 2008, p. 92).

Segundo Zimermam, além da interpretação, a pessoa do analista influi decisivamente no crescimento mental do analisando. O psicanalista funciona como um novo modelo de identificação.

Esta identificação pode ser sadia ou patogênica, ou seja, o paciente absorve e aos poucos identifica, introjeta com a forma como o analista o que escuta: "como discrimina, comunica e verbaliza os sentimentos e ideias; como se posiciona diante da situação de forte angústia [...] no jeito de ser verdadeiro ou não; a sua capacidade para sobreviver aos ataques agressivos, eróticos ou narcisista" ZIMERMAN, 2008, p. 93).

O paciente vai construindo novos valores e posições provenientes de novas identificações com a pessoa do analista, 
Pode acontecer também, de o psicanalista fazer uma leitura de seu paciente, que não seja a do real paciente e assim, o analista não reconhecer que seu paciente não é mais o mesmo; percepção equivocada, não reconhecendo o esforço que ele fez em obter mudanças, mínimas que sejam.

\subsection{A pessoal real do analista}

Os analistas apresentam divergências quanto a este tema. Alguns consideram que o que importa é a vivência transferencial que o paciente desloca e projeta no analista, independente de seus atributos e valores pessoais.

Outros, segundo Zimermam (2008) atribuem ao analista o papel de alta relevância para a análise.

\footnotetext{
Um grupo de psicanalistas norte americanos desenvolveu o conceito de "mach", palavra traduzida como encontro, segundo o qual, comprovado cientificamente que, um mesmo paciente pode evoluir analiticamente bem com um analista, mas com outro pode acontecer o inverso (ZIMERMAN, 2008, p. 49)
}

$\mathrm{Na}$ prática, deve-se ter uma percepção acerca do que o paciente pode suportar. "Nosso comportamento tem que sustentar certo compromisso; o analista deve ter consideração para com o paciente, para quem essa é uma experiência atemorizante" (ZIMERMAN, 2008, p. 23).

Ainda com Zimerman, persiste em algumas áreas de formação psicanalítica a recomendação em seguir a obediência, a neutralidade e o anonimato, regras formuladas por Freud. "O analista deve ser opaco aos seus pacientes e, como um espelho, não Ihes mostrar nada, exceto o que Ihe é mostrado" (FREUD, 1913, p.157 apud Zimerman, 2008, p.88). Os psicanalistas da atualidade não tem aplicado essas regras com rigidez. Valorizam a relação vincular .

O analista deve respeitar o ritmo e as capacidades momentâneas do paciente. Deve funcionar "como um adequado continente para conter a contínua carga de identificações projetivas provindas dos pacientes sob a forma de vazios, necessidades, desejos, dúvidas e angústia (ZIMERMAN, 2008, p. 90) 
Se o analista possui esta condição de forma bem estabelecida, ele terá condições de conter, decodificar o que o paciente diz, por meio de sua atividade interpretativa.

$\mathrm{Na}$ contemporaneidade houve uma mudança na organização psíquica dos indivíduos. Com a globalização, não há padrão, valorizando o que se vive no presente (FORBES, 2004). Com os novos laços sociais, novas modalidades de sintomas surgiram. Assim, requer ampliar a escuta psicanalítica.

Durante o trabalho analítico, as crenças, desejos e sentimentos pessoais do analista, não devem influenciar na compreensão dos sentimentos do paciente.

É importante que o analista tenha flexibilidade, o que se pode confundir ou seja, possuem uma maior flexibilidade, o que se confunde com negligência, resistência ou descaso. Ao contrário, deve corresponder a um estado mental de maior segurança e credibilidade nos princípios do ato analítico.

A responsabilidade em psicanálise é aquela frente ao acaso e a surpresa. A psicanálise se define por sua ética, como queria Lacan, e a ética segundo Forbes é o avesso da ética médica. E somente por esta via haverá uma colaboração efetiva entre os campos clínicos.

\section{METODOLOGIA DA PESQUISA}

Este estudo atende às normas da Associação Brasileira de Normas Técnicas e em especial, ao Manual de Normas Técnicas do Instituto Famet de Estudos Superiores e Educação Continuada, de Belo Horizonte-MG.

Essas normas tem por objetivo facilitar a execução do estudo dando-Ihe caráter científico, conferindo-Ihe confiabilidade, veracidade, sistematicidade, racionalidade, falibilidade, em qualquer que seja a área do conhecimento, afiançam Richardson et al. (2012).

Então, afiançado neste entendimento, dentro do que versam estudiosos como: Popper ( 1975); Gil (2008); Sampieri, Collado e Lucio (2012); o presente estudo se caracteriza: 
a) Quanto a natureza é uma pesquisa básica que segundo Gil (2008) consiste em construir conhecimentos novos úteis para o avanço da ciência sem aplicação prática prevista.

b) Quanto ao problema: é um estudo qualitativo

c) Quanto aos objetivos: é descritiva explicativa pois, essas pesquisas têm objetivo principal explicar e identificar os fatores que determinam ou que contribuem para a ocorrência dos fenômenos.

d) Quanto aos procedimentos técnicos: bibliográfica e não experimental. Contou com os valiosos autores e suas obras para o enriquecimento de informações sobre o tema em estudo.

e) Quanto ao método: hipotético dedutivo que, segundo Popper (1975) consiste na escolha de um assunto que apresenta uma certa inquietação ao pesquisando, levando-o a formulação de um problema. Para tal, precisará construir uma hipótese a partir de teorias já existentes. Com o auxílio de renomados autores buscará por meio de uma discussão bibliográfica encontrar resposta para o problema construído.

\section{CONCLUSÃO}

A partir de leituras feitas sobre o tema em estudo, alcançou-se o objetivo geral com o aporte teórico psicanalítico que foi conhecer a dinâmica psicanalítica e suas variações no setting analítico.

Quanto a hipótese, foi confirmada, pois o analisando pode dificultar o seu tratamento utilizando-se de situações que vão sofrendo variações na clínica. Sobre os mecanismos de defesa, entende-se que são utilizados de forma inconsciente pelo analisando. Sobre silêncio e a mentira, são recursos manipuladores tanto para o analista quanto ao próprio analisando. Os estados depressivos, podem dificultar o tratamento, porém, deverá ser verificado se é um estado passageiro ou se requer um tratamento paralelo com outro profissional para receber a medicação adequada ao tratamento. 
Evidenciou-se neste estudo a responsabilidade que compete tanto a quem diz quanto quem escuta. O psicanalista precisa ser ético e estar atento ao que o analisando diz. Falhas éticas ocasionam falhas técnicas. O psicanalista precisa estar preparado para a escuta do analisando. O tratamento fluirá dependendo da postura do psicanalista, de sua interação, da interpretação que ele faz dos sentimentos, das imagens, dos gestos e dos impulsos de seu paciente.

Cada atendimento é único, sendo que, as mudanças no setting analítico precisam ser adaptadas ao paciente para a evolução no processo psíquico.

\section{REFERÊNCIAS}

BERGERET, J..[ et al]; tradução Francisco Settineri, Psicopatologia. 9. ed., Artmed. Porto Alegre, 2006.

BION, W.R. Conversando com Bion (seminário clínico). Rio de Janeiro: Imago, 1992.

FENICHEL, O. Teoria psicanalítica das neuroses. Livraria Atheneu. São Paulo, 1999.

FERENCZI, S.(1919/1992). A técnica psicanalítica in: Sándor Ferenczi. Obras completas, v.II. São Paulo: Martins Fontes.

FERENCZI, S. Prolongamentos da técnica ativa em psicanálise (1921b).São Paulo: Escuta, 1987.. In: LACAN. Jacques. O seminário. Livro 8. A transferência 1960-1961. Rio de Janeiro: Jorge Zahar, 1992.

FORBES, Jorge. Você quer o que deseja? 4. ed. São Paulo: Best Seller, 2004.

FREUD, Anna. O ego e os mecanismos de defesa. 6. ed. Editora Civilização Brasileira. Rio de Janeiro, 1982. FREUD, Sigmund. Edição Brasileira da Obras Completas de S. Freud. Imago Editora. Rio de Janeiro, 1974.

FREUD, S. A Interpretação dos Sonhos." Tradução de: Walvredo Ismael de Oliveira. Título original: "Die Traumdeutug." Ed: Imago, $2^{a}$ ed; Rio d Janeiro, RJ: Imago, 1987.

.Recomendações aos médicos que exercem a psicanálise (1912). In: Obras psicológicas completas de Sigmund Freud: edição standart brasileira. Rio de Janeiro: Imago, 1996.

Sobre o início do tratamento (1913). In: Edição standart brasileira das obras psicológicas completas de Sigmundo Freud. Direção-geral da tradução de Jayme Salomão. Rio de Janeiro: Imago, 1969, v.XII

.Recordar, repetir e elaborar (1914). In: Edição standart brasileira das obras psicológicas completas de Sigmundo Freud. Direção-geral da tradução de Jayme Salomão. Rio de Janeiro: Imago, 1969, v.XII 
(1980/1912b) A dinâmica da transferência. Id. Vol. XII. 1980, p. 131-

146.

.(1980/1915a) Observações sobre o amor transferencial (Novas recomendações sobre a técnica da psicanálise III) Id. Vol. XII, p. 207-221.

FREUD, S. (2006a). Psicoterapia da histeria. Obras completas, ESB, v. II. Imago: Rio de Janeiro. (Trabalho original publicado em 1895)

GIL, Antonio Carlos. Métodos e técnicas de pesquisa social. 6 ed. São Paulo: Atlas, 2008.

GUTIERRA Beatriz C. C. (2003). Adolescência, Psicanálise e Educação: O Mestre "Possível" de Adolescente ( $1^{\underline{a}}$ ed.). São Paulo: Avercamp Editora.

ISOLAN, Luciano Rassier. Transferência erótica: uma breve revisão. Revista psiquiatria, Porto Alegre, v.27, n.2, 2005

LACAN, Jacques. O seminário - livro 7: a ética da psicanálise (1959-1960). Rio de Janeiro: Jorge Zahar, 1988

O seminário. Livro 8. A transferência. Rio de Janeiro: Jorge Zahar,

1992.

.(1962 - 1963). O Seminário. Livro X. A angustia. 3. ed. Tradução do Centro de Estudos Freudiano de Recife a partir da transcrição realizada pela Associação Freudiana Internacional, 2002

.O seminário. Livro 17. O avesso da psicanálise.

LAPLANCHE, J. e PONTALIS, J.B. Vocabulário da psicanálise. São Paulo: Martins Fontes, 2001/2003

ORLANDI, E.P. As formas do silêncio: no movimento dos sentidos. $4^{a}$ ed. São Paulo: UNICAM, 1997

MACEY, D. Lacan in contexts. Londres, Nova York: Verso, 1988

MAURANO, D. A transferência. Rio de Janeiro: Jorge Zahar, 2006

MORGADO, M.A. Da sedução na relação pedagógica: professor-aluno no embate com afetos inconscientes. $2^{\mathrm{a}}$ ed., São Paulo: Summus, 2002

NASIO, J.D. O silêncio na psicanálise. Rio de Janeiro: Jorge Zahar, 2010.

POPPER, K.S. A lógica da pesquisa científica. 2ª Edição. São Paulo: Cultrix, 1975

QUINET, Antônio. As 4+1 condições da análise. 12. ed., Editora: Jorge Zahar, Rio de Janeiro, 2009.

RICHARDSON, Roberto Jarry. [et al.] Pesquisa social: métodos e técnicas. 3 ed. São Paulo: Atlas, 2012. 
ROCHA, F.J.B. O psicanalista: um artífice e os limites de sua identidade. Revista Brasileira de Psicanálise. V.29. N.0, 1995

ROSA, M. I. P. D; ROSA, A. C. A Ética na psicanálise. Akrópolis, Umuarama, v. 17, n. $1, \quad$ p. $41-44, \quad 2009 . \quad$ Disponível em: http://revistas.unipar.br/akropolis/article/view /2841/2109. Acesso em 04 de julho de 2015

ROUDINESCO, E; PLON, M. Dicionário de psicanálise. Rio de Janeiro: Jorge Zahar, 1998.

SAMPIERI, Roberto Hernández; COLLADO, Carlos Fernández; LUCIO, Pilar Baptista. Metodologia da pesquisa. Trad. Fátima C. Murad, Melissa Kassner, Sheila C. D. Ladeira. 3ª ed. São Paulo: McGraw - Hill, 2012.

SANDLER, J. O paciente e o analista: fundamentos do processo psicanalítico. Rio de Janeiro: Imago, 1986.

WINNICOTT, D. W. O ambiente e os processos de maturação: estudos sobre a teoria do desenvolvimento emocional. Trad. Irinéia Constantino Schuh Ortiz. $3^{\underline{a}}$ ed. Porto Alegre: Artes médicas, 1990.

.(1963). Duas notas sobre o uso do silêncio in: explorações psicanalíticas. Organizadores: Clare Winnicott, Ray Shepheder, Madeleine Davis. Porto Alegre: Artes Médicas, 1994.

ZIMERMAN D, E. Fundamentos psicanalíticos: teoria, técnica e clínica: uma abordagem didática. Porto Alegre: Artmed; 1999

.Manual de Técnica Psicanalítica. Porto Alegre: Artmed, 2008. 